\title{
Invited perspectives: Current challenges to face knowns and unknowns in natural hazard risk management - an insurer perspective
}

\author{
Madeleine-Sophie Déroche ${ }^{1}$ \\ ${ }^{1}$ AXA Group Risk Management, Paris, 75008, France \\ Correspondence: Madeleine-Sophie Déroche (madeleinesophie.deroche@axa.com)
}

\begin{abstract}
All along the value chain of Property and Casualty $(\mathrm{P} \& \mathrm{C})$ insurance, various types of data feed a wide range of models to estimate the amount of loss for different probabilities and magnitudes of events for all risks undertaken (natural hazards, financial, cyber... ). These data and models support the current understanding and knowledge of risks as well as the assessment of not yet experienced situations. The current state of what is known today about natural hazards loss modelling in

5 the (re)insurance market is the outcome of more than 30 years of research, of the development of a wide community around natural hazards as well as of the occurrence of natural hazards. This paper highlights the need for an in-depth review of the current loss modelling framework, created at the early 1990s, to capture the increased complexity of each driver of the risk (exposure, hazard and vulnerability) as well as their interconnection.
\end{abstract}

\section{Introduction}

The mission of Property and Casualty (P\&C) insurers is to effectively protect clients' property and activities while ensuring the solvency of the company. It is at the core of insurers' business to identify and quantify risks associated with the underwritten policies. All along the value chain of $\mathrm{P} \& \mathrm{C}$ insurance, various types of data feed a wide range of models to estimate the amount of loss for different probabilities and magnitudes of events for all risks undertaken (natural hazards, financial, cyber...). These models support decision-making, from underwriting and pricing of the policy (for individuals or corporates) to the setting and optimization of the reinsurance programs at the insurance company level.

Sound and adaptive risk assessment and management are built over time through a continuous reassessment of insurers' understanding regarding: known knowns (what we know we know), known unknowns (what we know we do not know), unknown unknowns (what we don't know we do not know) (Girard, 2009). This reassessment process induces a knowledge cycle: data supports the current understanding and knowledge of a risk (what we know we know). Based on this understanding, models are built to support the assessment of not yet experienced situations such as extreme events (what we know we don't know). The occurrence of unknown unknowns, due to natural and organizational issues that insurers are neither aware of nor understand yet, calls for evolution in data collection (e.g. more granular, more variables, less segmentation...) and in modelling methods and tools (e.g. modelling scalability, uncertainty quantification...) to update the view of the risk and consequently the decision-making process. 
After a brief step backwards to illustrate how this reassessment process led to the start of natural hazards loss modelling framework, we highlight the scientific and technical advances that are needed to keep refining what we know on one hand and, on the other hand, increasing insurers' preparedness to what we do not know. This paper focuses on the impact of natural hazards to property exposure.

\section{The starting point of natural hazard loss modelling}

Before the 1990s, actuarial methods were used to extrapolate the limited loss experience to estimate extreme losses. This loss experience gathered all data available along with historical macro-economic information, which was used to estimate as-if losses (i.e. what would be the loss if the event were to occur today). It constituted the state of what was known at that time by insurers and public authorities.

The occurrence of Hurricane Andrew in 1992, whose impact was unexpected, was a game changer for modelling losses generated by natural hazards (Grossi et al., 2005; Mitchell-Wallace, 2017). One of the reasons for this event to be unanticipated was the increase of exposure in coastal areas where storm surge generated by Hurricane Andrew led to massive flood damages (McChristian, 2012). Loss data and statistical approaches available at that time did not enable to seize the impact of growing exposure in particularly risk prone areas. In the aftermath of the event, a collective awareness rose about the need to characterize separately the three drivers of the risk (hazard, vulnerability and exposure) as well as to model their interconnection. It was the start of natural hazard loss modelling based on a framework divided into 4 components as shown in the Figure 1.

From there started a long and incremental work of characterization of the here before cited four components for various types of perils and various regions. Each peril x region is usually modelled separately from the other (e.g. Asia Typhoon model is built separately from North Atlantic Hurricane model, hazard events are therefore not correlated). To facilitate and ensure a reasonably fast computation time for the production of modelled losses, the simulation engine used to intersect the 4 components has been rationalized and requires specific format for the data included in each component. This means that changing the format of the data of one component is likely to impact the simulation engine quite significantly both in terms of run efficiency and of how the link between components is done.

The consequences of Hurricane Andrew were unknown unknowns in 1992 and highlighted on one hand the non-modelled effects of the drivers of risk and on the other hand the insurance protection gap that was existing in Florida and the inefficiency of private and public mechanisms (McChristian, 2012). The creation of the 4-component loss modelling framework facilitates the identification of areas where deeper investigation is needed to refine data collection and modelling. In the next section, we suggest areas where research is needed to keep refining our current understanding of loss resulting from natural hazards.

\section{Challenges to improve what we know}

The current state of what is known today about natural hazards loss modelling in the (re)insurance market is the outcome of 
of natural hazards (Ward et al., 2020). The learning curve has been steep, closely linked to the increase of computer power (e.g. enabling the development and implementation of millions of possible climatic or seismic scenarios) and the collection of more and more granular observation data (e.g. hazard, claims, geocoded exposure).

In terms of data collection, we can mention the massive improvement over the last decade to retrieve and complete information characterizing the exposure, notably the location at (longitude, latitude) granularity and the physical properties of buildings. Geocoding tools and satellite data are used to complete the information that is difficult to get at the time of underwriting, especially for individual insurance. Based on the address, it is possible to get the precise geolocation, the structure of the building, number of floors or even the roof type, all are critical drivers of damage, and therefore of loss, for different perils (Ehrlich and Tenerelli, 2013; Castagno and Atkins, 2018; Kang et al., 2018; Schorlemmer et al., 2020).

While there has been a substantial increase of observation data made available over the last two decades (Yu et al., 2018), further investment should be made in the systematic collection of building damage and hazard magnitude information in the aftermath of natural events. This is already the case for earthquakes as it is of primary importance for public authorities to identify buildings that are about to collapse and those that are safe to stay in. It is less the case for other perils (e.g. flood, windstorm), as there are usually less structural damages on buildings and population is evacuated. In the case of floods, it may also be complicated to go into flooded areas for a long time after the event as it takes time for the water to recede. (Molinari et al., 2017) provide a compilation of case studies on damage assessment following various type of flooding events. Damage information and associated hazard magnitude are key to characterize the impact of natural hazards on buildings and improve the calibrations of buildings destruction rate and reconstruction costs in natural hazards models. New technologies such as drones and satellites provide alternative ways to access impacted areas and collect detailed and granular measurements in the next hours or days after the event occurred (Chesnel et al., 2007; Kakooei and Baleghi, 2017). A point of attention is the need for coordination among data collectors and the use of common definition of damages' scale to avoid the creation of multiple, overlapping and not comparable datasets. Research initiatives aiming at gathering various data sources already exist at country level, as for example the HOWAS database for flood damage in Germany (Kreibich et al., 2017; Kellermann et al., 2020). Could this type of work be extended at the scale of Europe or even more globally?

In terms of modelling, the occurrence of natural disasters feeds research that is integrated into the loss modelling framework every 2 to 5 years, mainly in the hazard and vulnerability components. For example, the successive occurrence of the two extreme European windstorms Lothar and Martin at the end of 1999 triggered the introduction of clustering effect in the modelling of the frequency of European winter windstorms. Clustering effect refers to the higher probability that two extreme windstorms occur in a short period of time, under particular atmospheric conditions (Pinto et al., 2013; Priestley et al., 2017). Before then, the occurrence process of European windstorms was assumed to follow a Poisson distribution, which did not allow for successive events to occur. As exhibited in (Priestley et al., 2018), clustering effect has a significant impact on the estimation of yearly aggregated losses and therefore on the dimensioning of reinsurance covers.

Here after are two topics where further investigation could be performed: (i) the assessment of uncertainty all along the modelling chain and (ii) the scalability of the loss modelling framework. Regarding the first topic, uncertainty is inherent to modelling and is today captured to some extent in the loss modelling framework through the primary uncertainty (related to the 
assumptions and the simulation of the hazard catalogue) and the secondary uncertainty (related to the damage and loss assessment). For example, (Kaczmarska et al., 2018) provides a quantification of the impact of changing exposure location, flood defense level and damage ratios on loss estimates. This enables to identify sensitive components which may require multiple samplings when simulating the loss. (Winter et al., 2018) go a step further by notably identifying and quantifying uncertainties present in the production of the hazard events catalogue. Such an analysis requires first to run the production of the hazard catalogue several times to test different set of parameters and second, to run the loss simulation engine multiple times, which is costly both in terms of computer power and inclusion in the loss modelling framework. While (Beven et al., 2018) suggest a framework to deal with epistemic uncertainty in natural hazard modelling, recent work as in (Noacco et al., 2019; KC et al., 2020) has been carried out to address uncertainty quantification with appropriate methods and tools which could be further implemented directly as new features or components in the loss modelling framework.

As for modelling scalability, the issue is to reconcile the precise evaluation at the moment of underwriting clients' policies (i.e. for a corporate client a few buildings) and the evaluation at portfolio level (i.e. for a global insurer, millions of buildings). For example, to estimate the premium of one policy for an industrial facility it is crucial to capture: (i) the specific features of the buildings at stake (3D shape of the building, location, structure...), (ii) any prevention measures that may have been put in place by the policyholder and (iii) hazards' information on magnitude and frequency. Such detailed and localized information cannot be captured today in the loss modelling framework, one reason being for example the spatial resolution of the hazard events catalogue that varies from one peril to the other, the finest ones achieving 30 meters and even 5 meters in some urban areas. This generates a non-alignment of approaches used to evaluate the risk of the same policy at the different levels of assessment (from localized building level to global portfolio level). This raises the following questions: Would it be appropriate and feasible to have a unique and scalable model, able to resolve the various scales of each purpose? Or could there be a downscaling methodology used to refine the modelling performed at the large scale of a portfolio to the building level? Challenges suggested in this section to improve what we know we don't know highlight the potential limitations of the current loss modelling framework and its simulation engine. For example, considering the shape of buildings in addition to their coordinates (longitude, latitude) would require changing not only the format used to capture the exposure information but also how the exposure is intersected with hazard. There is therefore a need for an in-depth review of the current loss modelling framework to support these already identified evolutions and increase insurers' understanding of natural hazard risk, all the more in an ever more connected environment that will be described in the next section.

\section{Challenges to face what we do not know}

As said in (Baum, 2015), "threats are rarely completely unknown or unquantifiable". Sometimes what we do not know is already present in the data or the model but has not been understood nor analyzed yet. Since the design of the loss modelling framework in the 1990s, clients have become more interconnected (Gereffi et al., 2001), and the correlations between natural hazards and regions is also better understood and quantified (Steptoe, 2016; Steptoe et al., 2018; Zscheischler et al., 2020). With globalization, clients around the world have become more and more connected and dependent to each other within so 
called Global Value Chains (Gereffi et al., 2001; Baldwin and Lopez-Gonzalez, 2015; Phillips, 2018). This dependency has been particularly exhibited with the floods in Thailand in 2011 where the interruption of production of microprocessors in Thailand has led to a brutal interruption of production and a shortage of microprocessors in the world and consequently, a shortage of cameras or smartphones in the world (Chopra and Sodhi, 2014; Haraguchi and Lall, 2015). From an insurer's standpoint, suppliers' default because of the occurrence of a natural hazard is not insured, as it is not quantifiable with current modelling which does not capture this connection between suppliers and producers. Supply chain data has improved (Tiwari et al., 2018; Beorchia and Crook, 2020) and need to be further analyzed and included in natural hazard loss modelling. It could be source of opportunities for insurers to deliver new services to customers while making a research progress to visualize and measure levels of complexity (volume, direction and intensity of interconnections). Interconnections between hazards or between clients are not yet captured in the current loss modelling framework, which remains siloed by hazard and region and does not include any supply chain information. Not integrating these interactions may lead to a bias in our understanding of the underlying risk. There is a need for a deeper review of the loss modelling framework to consider this new and complex information.

Another way to tackle unknown unknowns is to develop forward-looking views of the risk. The obvious case study for this is the quantification of the impact of climate change on insurers' business. To perform this exercise, insurers do not only need to project the future plausible scenarios of hazard events (information provided by climate models simulations) but also to project the evolution of exposure and vulnerability. In this context, the most pressing questions global insurers need to answer are: how to gather worldwide future projections of population growth or decline and/or wealth? How will building codes evolve? Will the implementation of prevention measures reduce the impact of natural hazards, in particular in the context of climate change?

These elements need to be explored and taken systematically into account while elaborating loss models for natural hazards. Insurers will thus not only be aware of the existence of interconnections but also better understand and visualize them.

\section{Conclusions}

Over the years, models have mainly evolved on the basis of the addition of new information without, however, carrying out an in-depth transformation able to reflect the new understanding that insurers need of the complex connections between natural hazards, exposure and vulnerability. This new understanding stems from the observation of the growing number of interconnections - and mutual impacts - at different levels: between insured customers and their suppliers but also interactions and cross impacts between natural phenomena at the origin of disasters. Nevertheless, loss modelling framework continues to be based on a peril $x$ region and client by client logic rather than a global one. This leads to a structural gap between models and reality, which hinders the design and testing of new types of products or protection mechanisms that would consider the entire value chain.

We suggest opening the reflection on the opportunity of carrying out global loss models for natural hazards that would be able to account for the complexity of the interactions of both natural elements and customers ecosystem. Such a reflection can 
https://doi.org/10.5194/nhess-2022-6

Preprint. Discussion started: 24 January 2022

(C) Author(s) 2022. CC BY 4.0 License.

(c) (1)

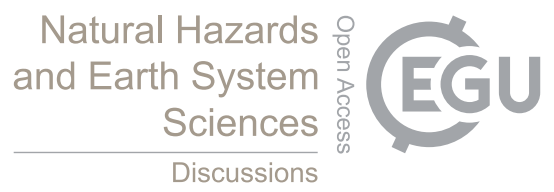

only be performed on the basis of transdisciplinary research including not only IT, data science and geosciences but also civil engineers, urban planning sciences and socio-economic sciences. Insurers will therefore be able to better anticipate the needs of their customers while being better equipped to cope with not only uncertainty but also the unknown. 


\section{References}

Baldwin, R. and Lopez-Gonzalez, J.: Supply-chain Trade: A Portrait of Global Patterns and Several Testable Hypotheses, The World Economy, 38, 1682-1721, https://doi.org/10.1111/twec.12189, 2015.

Baum, S. D.: Risk and resilience for unknown, unquantifiable, systemic, and unlikely/catastrophic threats, Environment Systems and Decisions, 35, 229-236, https://doi.org/10.1007/s10669-015-9551-8, 2015.

Beorchia, A. and Crook, T. R.: Bloomberg Supply Chain Analysis: A Data Source for Investigating the Nature, Size, and Structure of Interorganizational Relationships, in: Research Methodology in Strategy and Management, edited by Crook, T. R., Lê, J., and Smith, A. D., pp. 73-100, Emerald Publishing Limited, https://doi.org/10.1108/S1479-838720200000012017, 2020.

Beven, K. J., Aspinall, W. P., Bates, P. D., Borgomeo, E., Goda, K., Hall, J. W., Page, T., Phillips, J. C., Simpson, M., Smith, P. J., Wagener, T., and Watson, M.: Epistemic uncertainties and natural hazard risk assessment - Part 2: What should constitute good practice?, Natural Hazards and Earth System Sciences, 18, 2769-2783, https://doi.org/10.5194/nhess-18-2769-2018, 2018.

Castagno, J. and Atkins, E.: Roof Shape Classification from LiDAR and Satellite Image Data Fusion Using Supervised Learning, Sensors, 18, 3960, https://doi.org/10.3390/s18113960, 2018.

Chesnel, A.-L., Binet, R., and Wald, L.: Object oriented assessment of damage due to natural disaster using very high resolution images, in: 2007 IEEE International Geoscience and Remote Sensing Symposium, pp. 3736-3739, IEEE, Barcelona, Spain, https://doi.org/10.1109/IGARSS.2007.4423655, 2007.

Chopra, S. and Sodhi, M. S.: Reducing the Risk of Supply Chain Disruptions, SUPPLY CHAIN MANAGEMENT, p. 9, 2014.

Ehrlich, D. and Tenerelli, P.: Optical satellite imagery for quantifying spatio-temporal dimension of physical exposure in disaster risk assessments, Natural Hazards, 68, 1271-1289, https://doi.org/10.1007/s11069-012-0372-5, 2013.

Gereffi, G., Humphrey, J., Kaplinsky, R., and Sturgeon*, T. J.: Introduction: Globalisation, Value Chains and Development, IDS Bulletin, 32, 1-8, https://doi.org/10.1111/j.1759-5436.2001.mp32003001.x, 2001.

Girard, J.: A Leader's Guide to Knowledge Management: Drawing on the Past to Enhance Future Performance, Business Expert Press, 1 edn., https://doi.org/10.4128/9781606490198, 2009.

Grossi, P., Kunreuther, H., and Windeler, D.: An Introduction to Catastrophe Models and Insurance, in: Catastrophe Modeling: A New Approach to Managing Risk, edited by Grossi, P. and Kunreuther, H., vol. 25, pp. 23-42, Kluwer Academic Publishers, Boston, https://doi.org/10.1007/0-387-23129-3_2, series Title: Catastrophe Modeling, 2005.

Haraguchi, M. and Lall, U.: Flood risks and impacts: A case study of Thailand's floods in 2011 and research questions for supply chain decision making, International Journal of Disaster Risk Reduction, 14, 256-272, https://doi.org/10.1016/j.ijdrr.2014.09.005, 2015.

Kaczmarska, J., Jewson, S., and Bellone, E.: Quantifying the sources of simulation uncertainty in natural catastrophe models, Stochastic Environmental Research and Risk Assessment, 32, 591-605, https://doi.org/10.1007/s00477-017-1393-0, 2018.

Kakooei, M. and Baleghi, Y.: Fusion of satellite, aircraft, and UAV data for automatic disaster damage assessment, International Journal of Remote Sensing, 38, 2511-2534, https://doi.org/10.1080/01431161.2017.1294780, 2017.

Kang, J., Körner, M., Wang, Y., Taubenböck, H., and Zhu, X. X.: Building instance classification using street view images, ISPRS Journal of Photogrammetry and Remote Sensing, 145, 44-59, https://doi.org/10.1016/j.isprsjprs.2018.02.006, 2018.

KC, U., Garg, S., Hilton, J., and Aryal, J.: A cloud-based framework for sensitivity analysis of natural hazard models, Environmental

Modelling \& Software, 134, 104 800, https://doi.org/10.1016/j.envsoft.2020.104800, 2020. 
Kellermann, P., Schröter, K., Thieken, A. H., Haubrock, S.-N., and Kreibich, H.: The object-specific flood damage database HOWAS 21, Natural Hazards and Earth System Sciences, 20, 2503-2519, https://doi.org/10.5194/nhess-20-2503-2020, 2020.

Kreibich, H., Thieken, A., Haubrock, S.-N., and Schröter, K.: HOWAS21, the German Flood Damage Database, in: Geophysical Monograph Series, edited by Molinari, D., Menoni, S., and Ballio, F., pp. 65-75, John Wiley \& Sons, Inc., Hoboken, NJ, USA, https://doi.org/10.1002/9781119217930.ch5, 2017.

McChristian, L.: HURRICANE ANDREW AND INSURANCE: THE ENDURING IMPACT OF AN HISTORIC STORM, p. $19,2012$.

Mitchell-Wallace, K., ed.: Natural catastrophe risk management and modelling: a practitioner's guide, John Wiley and Sons, Inc, Hoboken, NJ, 2017.

Molinari, D., Menoni, S., and Ballio, F., eds.: Flood damage survey and assessment: new insights from research and practice, no. 228 in Geophysical monograph series, Wiley ; American Geophysical Union, Hoboken, NJ : Washington, D.C, oCLC: ocn960493784, 2017.

Noacco, V., Sarrazin, F., Pianosi, F., and Wagener, T.: Matlab/R workflows to assess critical choices in Global Sensitivity Analysis using the SAFE toolbox, MethodsX, 6, 2258-2280, https://doi.org/10.1016/j.mex.2019.09.033, 2019.

Phillips, N.: Global value chains:, in: Dictionnaire d'économie politique, pp. 247-250, Presses de Sciences Po, https://doi.org/10.3917/scpo.smith.2018.01.0247, 2018.

Pinto, J. G., Bellenbaum, N., Karremann, M. K., and Della-Marta, P. M.: Serial clustering of extratropical cyclones over the North Atlantic and Europe under recent and future climate conditions: CLUSTERING OF EXTRATROPICAL CYCLONES, Journal of Geophysical Research: Atmospheres, 118, 12,476-12,485, https://doi.org/10.1002/2013JD020564, 2013.

Priestley, M. D. K., Pinto, J. G., Dacre, H. F., and Shaffrey, L. C.: Rossby wave breaking, the upper level jet, and serial clustering of extratropical cyclones in western Europe: WESTERN EUROPE CLUSTERING DYNAMICS, Geophysical Research Letters, 44, 514521, https://doi.org/10.1002/2016GL071277, 2017.

Priestley, M. D. K., Dacre, H. F., Shaffrey, L. C., Hodges, K. I., and Pinto, J. G.: The role of serial European windstorm clustering for extreme seasonal losses as determined from multi-centennial simulations of high-resolution global climate model data, Natural Hazards and Earth System Sciences, 18, 2991-3006, https://doi.org/10.5194/nhess-18-2991-2018, 2018.

Schorlemmer, D., Beutin, T., Cotton, F., Garcia Ospina, N., Hirata, N., Ma, K.-F., Nievas, C., Prehn, K., and Wyss, M.: Global Dynamic Exposure and the OpenBuildingMap - A Big-Data and Crowd-Sourcing Approach to Exposure Modeling, other, oral, https://doi.org/10.5194/egusphere-egu2020-18920, 2020.

Steptoe, H.: The risk of global weather connections. Are atmospheric hazards independent?, Tech. rep., MetOffice, 2016.

Steptoe, H., Jones, S. E. O., and Fox, H.: Correlations Between Extreme Atmospheric Hazards and Global Teleconnections: Implications for Multihazard Resilience: ATMOSPHERIC HAZARDS AND GLOBAL TELECONNECTIONS, Reviews of Geophysics, 56, 50-78, https://doi.org/10.1002/2017RG000567, 2018.

Tiwari, S., Wee, H., and Daryanto, Y.: Big data analytics in supply chain management between 2010 and 2016: Insights to industries, Computers \& Industrial Engineering, 115, 319-330, https://doi.org/10.1016/j.cie.2017.11.017, 2018.

Ward, P. J., Blauhut, V., Bloemendaal, N., Daniell, J. E., de Ruiter, M. C., Duncan, M. J., Emberson, R., Jenkins, S. F., Kirschbaum, D., Kunz, M., Mohr, S., Muis, S., Riddell, G. A., Schäfer, A., Stanley, T., Veldkamp, T. I. E., and Winsemius, H. C.: Review article: Natural hazard risk assessments at the global scale, Natural Hazards and Earth System Sciences, 20, 1069-1096, https://doi.org/10.5194/nhess20-1069-2020, 2020.

Winter, B., Schneeberger, K., Huttenlau, M., and Stötter, J.: Sources of uncertainty in a probabilistic flood risk model, Natural Hazards, 91, 431-446, https://doi.org/10.1007/s11069-017-3135-5, 2018. 
https://doi.org/10.5194/nhess-2022-6

Preprint. Discussion started: 24 January 2022

(C) Author(s) 2022. CC BY 4.0 License.

(c) (1)

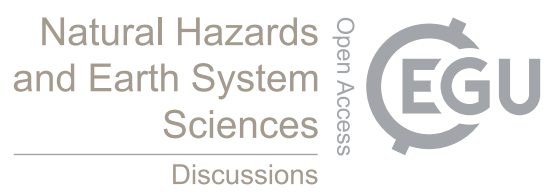

Yu, M., Yang, C., and Li, Y.: Big Data in Natural Disaster Management: A Review, Geosciences, 8, 165, https://doi.org/10.3390/geosciences8050165, 2018.

Zscheischler, J., Martius, O., Westra, S., Bevacqua, E., Raymond, C., Horton, R. M., van den Hurk, B., AghaKouchak, A., Jézéquel, A., Mahecha, M. D., Maraun, D., Ramos, A. M., Ridder, N. N., Thiery, W., and Vignotto, E.: A typology of compound weather and climate events, Nature Reviews Earth \& Environment, 1, 333-347, https://doi.org/10.1038/s43017-020-0060-z, 2020. 
https://doi.org/10.5194/nhess-2022-6

Preprint. Discussion started: 24 January 2022

(c) Author(s) 2022. CC BY 4.0 License.

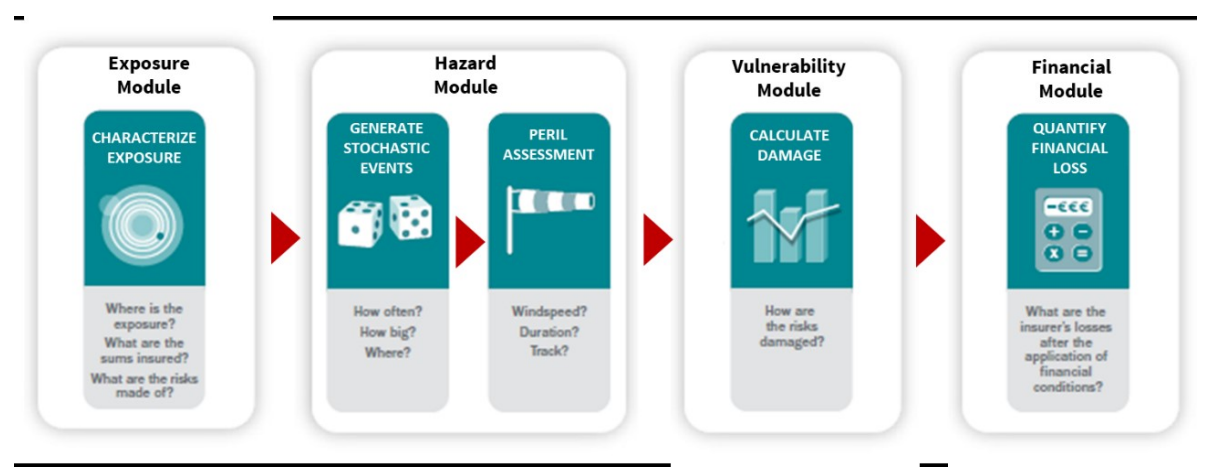

Figure 1. Loss Modelling Framework composed of 4 components. A simulation engine is used to intersect the exposure information with the catalogue of hazard events and apply the damage ratio characterized with the vulnerability curve, function of hazard and building characteristics. This operation leads to a loss, gross of any financial insurance conditions. Their application is performed in the financial module. 